\title{
Power Quality Improvement by Using Statcom Control Scheme in Wind Energy Generation Interface to Grid
}

\author{
* Dr. Sheeraz Kirmani 1, Brijech Kumar 2 \\ 1, 2 Department of Electrical Engineering, Jamia Millia islamia, New Delhi, India \\ E mail: sheerazkirmani@gmail.com ,E mail: bknsea@icloud.com
}

\begin{tabular}{l} 
A R T I C L E I N F O: \\
\hline Article history: \\
Received 2 August 2017 \\
Accepted 26 August 2017 \\
Available online 12 October \\
2017
\end{tabular}

Keywords:

Power quality

Improvement;

Statcom control

scheme;

Wind energy

Generation.

This work is licensed under a Creative Commons Attribution

NonCommercial - NoDerivs 4.0. "CC-BY-NC-ND"

\section{A B S T R A C T}

"Electric Power Quality (EPQ) is a term that refers to maintaining the near sinusoidal waveform of power distribution bus voltages and currents at rated magnitude and frequency." Today customers are more aware of the seriousness that the power quality possesses, this prompts the utilities to assure good quality of power to their customer. The power quality is basically customer-centric. The increased focus on utilities toward to maintaining reliable power supply by employing power quality improvement tools has reduced the power outages and blackout considerably. Good power quality is the characteristic of reliable power supply. Low power factor, harmonic pollution, load imbalance, fast voltage variations are some common parameters which are used to define the power quality. If the power quality issues are not checked, i.e., the parameters that define power quality doesn't fall within the predefined standards than it will lead to high electricity bill, high running cost in industries, malfunctioning of equipments, challenges in connecting renewables. Capacitor banks, FACTS devices, harmonic filters, SVC's, STATCOM are the solutions to achieve the power quality. The performance of Wind turbine generators is affected by poor quality power, at the same time these wind power generating plant affects the power quality negatively. This paper presents the STATCOM system with the BESS and studies the impact on the power quality in a system which consist of wind turbine generator, nonlinear load, hysteresis controller for controlling the operation of STATCOM and grid. The model is simulated in the MATLAB/Simulink. This scheme mitigates the power quality issues, improves voltage profile and also reduces harmonic distortion of the waveforms. BESS level out the imbalances caused by real power due to intermittent nature of wind power available due to varying wind speeds.

JOURNAL OF CONTEMPORARY URBAN AFFAIRS (2017) 1(3), 31-37.

https://doi.org/10.25034/ijcua.2018.3676

Www.ijcua.com

Copyright (C) 2017 Journal Of Contemporary Urban Affairs. All rights reserved.

\section{Introduction}

Power is the very crucial input for the growth of any economy. Therefore, it is considered as a core industry as it facilitates development across various sectors, such as agriculture,
*Corresponding Author:

Department of Electrical Engineering, Jamia Millia islamia, New Delhi, India

E-mail address: sheerazkirmani@gmail.com 
manufacturing, railways, education, commercial, etc. to expel economic development. To meet the high GDP rates, the energy needs of the country are inevitable.

Renewable energy is characterized as intermittent and variability which presents various challenges in its grid integration for maintaining grid stability and security.

Intermittent/variable nature of RE source results in wide variation in quantum and direction of power flow on the inter-state high capacity transmission corridors. This requires placement of dynamic reactive compensation in the form of dynamic reactive compensation in the form of STATCOM/sVC at strategic locations to provide dynamic support for smooth operation and to maintain grid security.

The integration wind into existing electrical power system induces power quality problems like voltage regulation, stability, harmonic distortion, voltage sag/swell and also power factor. The power quality is always customerfocused measure and is greatly affected by the operation of a distribution and transmission network. In this

proposed scheme one of the Flexible AC transmission system (FACTS) device, i.e., StaticCompensator (STATCOM) is connected at the point of common coupling (PCC) with a battery energy storage system (BESS) to mitigate power quality problems. Since STATCOM connected to the grid provides reactive power support to wind generator and to load. The BESS is integrated to sustain real power source under fluctuating wind or solar power.

In the event of if there is any sudden load change or change in voltage profile like a short circuit in point of common coupling (PCC), a Distribution-STATCOM responds fast and stabilizes the voltage and also helps in order to maintain power quality.

\section{Problems Related To Power Quality}

A. Power Quality Issues of Grid Side:

At the grid side, the power quality is the responsibility of utility. The utility should make sure that the power matches the customer requirements and should not violate the limits that are specified for the parameters which define the power quality. From the customer point of view, the voltage variations and high content of harmonics in the grid power are highly undesired as they affect the performance of the end equipment. For the IIP's who have planned the wind power project, the voltage profile of evacuating substation and nearby substations is of prime concern.

\section{1) Voltage variation:}

Intermittent nature of wind power causes several problems, and one is a variation of the voltage of buses in the region of high wind penetration. Wind generators mostly employed induction generators and power electronic circuits which demand reactive power for operation. Voltage sag/swell is observed where ineffective methods of reactive power management are employed. If the voltage rises beyond the controllable limit, forced tripping of lines carried out, cascaded tripping may destabilize a weak power system. Generally, the power factor of evacuating substation is maintained near to unity preferably slightly lagging.

2) Voltage Transients:

B. Power Quality Issues of WTG Side

In the wind energy generating system the power quality primarily concerned with the quality of current waveform which is being drawn or generated by the wind turbine. Poor power quality affects the performance of the loads connected to the grid.

\section{1) Reactive Power Consumption:}

Induction generators draw reactive power to produce its working flux while generating active power at the same time. As induction generators are most widely preferred in wind turbine generators, collectively a wind farm demand a huge amount of reactive power. As the wind speed is not constant, in such a case the use of electronic power conversion devices in wind turbine generators becomes inevitable to achieve a rotor speed for maximum extraction of energy from wind. The operation of power electronic devices also requires reactive power. To avoid voltage stability problem either STATCOM or capacitor arrangement is used to supply this demand of reactive power.

\section{2) Current Harmonics Generation:}

Capacitors are used as an essential part of the wind turbine generators for supplying reactive power demand. Capacitor switching may cause large voltage transient. The frequency and amplitude of such transient are enormous, particularly when back to back switching is involved, for instance, capacitor bank switching. The overvoltages may damage the insulation, moreover, electronic equipment such as controllers are very sensitive to these transients, may produce incorrect commands. In addition, 
lightning strikes will cause an overvoltage in the electrical system of the wind turbine.

\section{Topology for Power Quality Improvement}

The STATCOM based current control voltage source inverter injects the current into the grid in such a way that the source current is harmonic free and their phase-angle with respect to source voltage has a desired value. The injected current will cancel out the reactive part and harmonic part of the load and induction generator current, thus it improves the power factor and the power quality. To accomplish these goals, the grid voltages are sensed and are synchronized in generating the current command for the inverter. The proposed gridconnected system is implemented for power quality improvement at the point of common coupling (PCC), as shown in Figure 1.The connected grid system in Figure 1, consists of wind energy generation system and battery energy storage system withSTATCOM.

\section{B. Bess-Statcom}

The battery energy storage system (BESS) is used as an energy storage element to support the wind farm during intermittencies it also supports grid during any disturbance and loss of generation. The BESS will naturally maintain dc capacitor voltage constant and is best suited in STATCOM since it readily manages demand and supply of real power and also injects or absorbed reactive power to stabilize the grid system. It also controls the distribution and transmission system at a very fast rate. When power fluctuations occurs in the system, the BESS can be used to level the power fluctuations by charging and discharging operation. The BESS system is connected in parallel to the dc capacitor of STATCOM (Salamah et al., 1992; Yang et al., 2001; Black, and Strbac, 2007; Spahic et al., 2007; Mohod, and Aware, 2008)

STATCOM comes from the family of FACTS devices. These are basically solid-state devices which are having the capability to respond to the reactive power demand. STATCOM have the edge over the SVC's as the former have constant current characteristics while in the SVC's the capacitive current drops linearly with the voltage. STATCOM can easily be interfaced with real power sources like the battery systems, fuel cells, etc. STATCOM effectively control the system voltage and avoid voltage collapse.

STATCOM are solid-state shunt connected devices. STATCOM's strategically placed in the power system to make the grid robust to the disturbances. STATCOM are finding applications in the renewable energy integration.

C. System Operation

In the system under study, STATCOM is interfaced with the BESS system. The STATCOM-BESS system is then connected to the PCC in the grid where non-linear loads and induction generator based wind turbine are also interfaced.The current control strategy is adapted to control the statcom-BESS system. The control strategy controls the output of station in such a manner so as to achieve power quality norms in the electrical grid.The statcom is intended here to support both reactive as well as real power demand of the other sub-systems. The main block diagram of the operational system scheme is shown in Figure 2.

\section{Control Scheme}

\section{A. Bang-Bang Current Controller}

The current control scheme is implemented using a bang-bang current controller. In this control scheme, the source current is detected by a current sensor, and these are compared with the reference current to obtain the current error for the hysteresis-based bang-bang controller.

Thus the ON/OFF switching signals for IGBT of STATCOM are derived from hysteresis controller. The switching function $S_{A}$ for phase 'an' is expressed as.

$$
\begin{aligned}
& i_{s a}<\left(i_{s a}^{*}-H B\right) \rightarrow S_{A}=0 \\
& i_{s a}>\left(i_{s a}^{*}-H B\right) \rightarrow S_{A}=1
\end{aligned}
$$

where $\mathrm{HB}$ is a current hysteresis band, similarly the switching function $S_{B}, S_{C}$ can be derived for phases " $b$ " and " $c$ " (Mohod, and Aware, 2008; Mohod, and Aware, 2006)

\section{B. Gird Synchronisation} In three-phase balance system, the RMS voltage source ampl- 


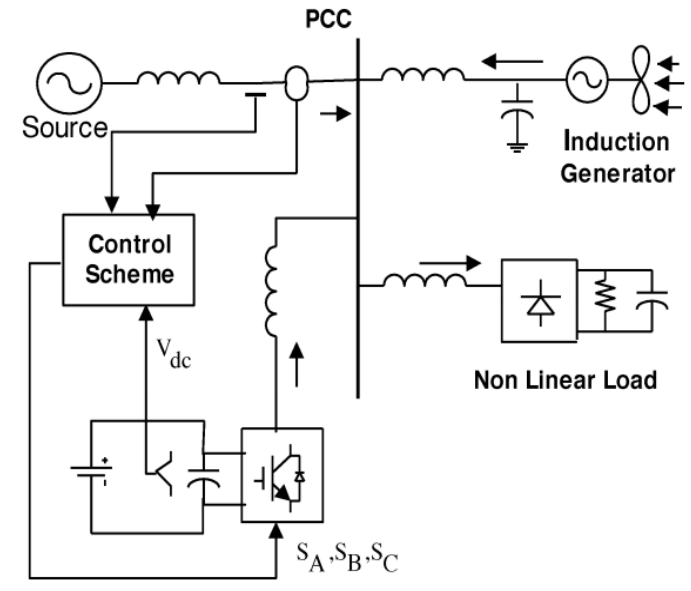

Figure 1. Diagrammatic representation of operating scheme.

-studies calculated at the sampling frequency of the source phase voltage $\left(V_{s a}, V_{s b}, V_{s c}\right)$ and is expressed as sample template $V_{s m}$, sampled peak voltage, as in (1).

$V_{s m}=\sqrt{ }\left\{\frac{2}{3}\left(V_{s a}^{2}+V_{s b}^{2}+V_{s c}^{2}\right)\right\}$

The in-phase unit vectors are obtained from AC source-phase voltage and the RMS value of unit vector $u_{s a}, u_{s b}, u_{s c}$ as shown in (2).

$\mathrm{u}_{\mathrm{sa}}=\frac{\mathrm{v}_{\mathrm{sa}}}{\mathrm{v}_{\mathrm{sm}}}, \mathrm{u}_{\mathrm{sb}}=\frac{\mathrm{v}_{\mathrm{sb}}}{\mathrm{v}_{\mathrm{sm}}}, \mathrm{u}_{\mathrm{sc}}=\frac{\mathrm{v}_{\mathrm{sc}}}{\mathrm{v}_{\mathrm{sm}}}$

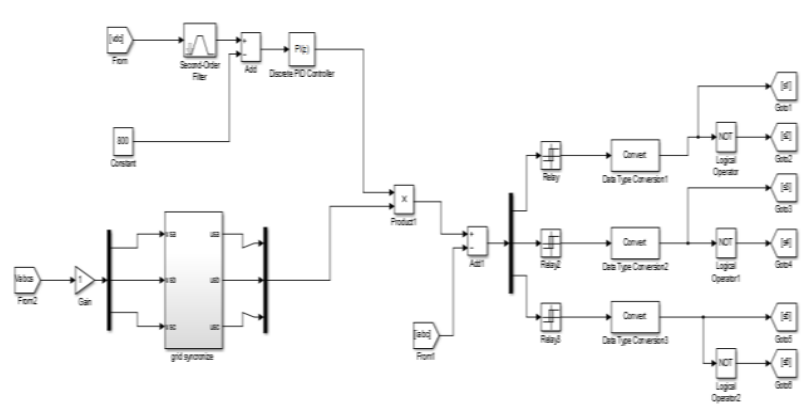

Figure 2. Hysteresis controller (Matlab Model).

The in-phase generated reference currents are derived using in-phase unit voltage template as, in (figure 3)

$i_{s a}=I \cdot u_{s a}, i_{s b}=I \cdot u_{s b}, i_{s c}=I \cdot u_{s c}(3)$

Where I am proportional to the magnitude of filtered source voltage for respective phases. This ensures that the source current is controlled to be sinusoidal. The unit vectors implement the important function in the grid connection for the synchronization for STATCOM. This method is simple, robust and favorable as compared with other methods (Milands et al., 2007).

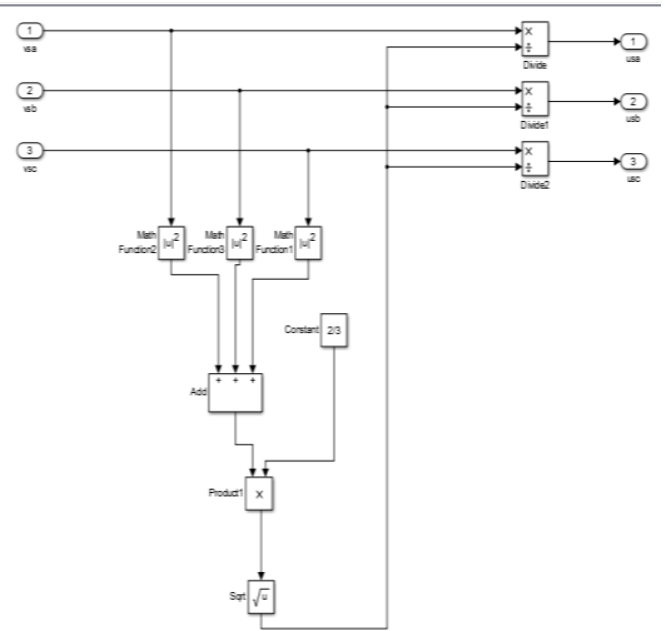

Figure 3. Unit Vector Block for Grid Synchronisation.

\section{System P Performance}

The proposed control scheme is simulated using Simulink power system block set. The system parameter for given system is given Table I.

\section{A. Voltage Source Current Control-Inverter Operation}

STATCOM in its basic structure is a voltage source inverter and is composed of IGBT's. Igbt based three-phase inverter is connected to the grid at PCC through the interconnecting transformers. The statcom inject the three phase currents to level out the distortions due to nonlinear loads and wind turbine generating system in the grid power supply. The control signals with a hysteresis band of 0.08 for switching of igbts are simulated from the comparison made between reference currents and actual three-phase source currents. Hysteresis band is generally kept low for better combating capabilities of statcom. The control signal of switching frequency within its operating band, as shown in Figure. 4.

The choice of the current band depends on the operating voltage and the interfacing transformer impedance. The compensated current for the nonlinear load and demanded reactive power is provided by the inverter. The real power transfer from the batteries is also supported by the controller of this inverter. The three-phase inverter injected current are shown in Figure 5.

B. STATCOM-Performance under Load Variations

The system is modeled in MATLAB to investigate the performance of STATCOM based BESS system under dynamic loads and peak wind generation 
or fixed wind generation. Induction generator based wind turbine generator demand reactive power. Therefore when the STATCOM is switched on at time $0.7 \mathrm{sec}$, it starts supplying this reactive power demand. Additionally, it also injects current such that harmonics at the supply side current reduces considerably. To investigate the performance under varying

Table I. Rating and parameters.

\begin{tabular}{|c|l|l|}
\hline S.N. & \multicolumn{1}{|c|}{ Parameters } & \multicolumn{1}{c|}{ Ratings } \\
\hline 1 & Grid Voltage & 3 -phase $, 415 \mathrm{~V}, 50 \mathrm{~Hz}$ \\
\hline 2 & $\begin{array}{l}\text { Induction } \\
\text { Motor } / \text { Generator }\end{array}$ & $\begin{array}{l}3.35 \mathrm{kVA}, 415 \mathrm{~V}, 50 \mathrm{~Hz}, \mathrm{P}=4, \\
\text { Speed }=1440 \mathrm{rpm}, \mathrm{Rs}=0.01 \Omega, \\
\mathrm{Rr}=0.015 \Omega, \mathrm{Ls}=0.06 \mathrm{H}, \mathrm{Lr}=0.06 \mathrm{H}\end{array}$ \\
\hline 3 & $\begin{array}{l}\text { Line Series } \\
\text { Inductance }\end{array}$ & $0.05 \mathrm{mH}$ \\
\hline 4 & Inverter Parameters & $\begin{array}{l}\text { DC Link Voltage }=800 \mathrm{~V}, \\
\text { DC link Capacitance }=100 \mu \mathrm{F} . \\
\text { Switching frequency }=2 \mathrm{kHz},\end{array}$ \\
\hline 5 & IGBT Rating & $\begin{array}{l}\text { Collector Voltage }=1200 \mathrm{~V}, \text { Forward } \\
\text { Current }=50 \mathrm{~A}, \mathrm{Gate} \text { voltage }=20 \mathrm{~V}, \\
\text { Power dissipation }=310 \mathrm{~W}\end{array}$ \\
\hline 6 & Load Parameter & Non-linear Load 25kW. \\
\hline
\end{tabular}

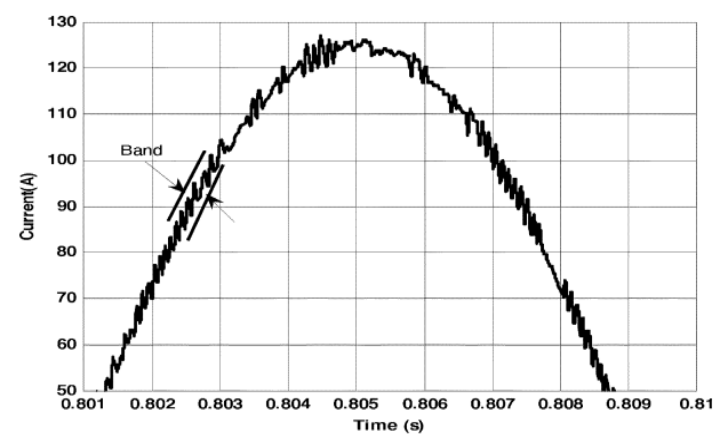

Figure 4. Switching signal and control hysteresis band.

loads the provisions are made in the MATLAB program to increase the load at time $1 \mathrm{sec}$. For increased load STATCOM based system effectively compensate the increased demand for real and reactive power. The result of source current, the load current is shown in Figure 6(a) and (b) respectively. While the result of injected current from STATCOM are shown in Figure 6(c) and the generated current from wind generator at PCC are depicted in Figure 6(d).

The DC link voltage regulates the source current in the grid system, so the DC link voltage is maintained constant across the capacitor as shown in Figure 7(a). The current through the dc link capacitor is indicating the charging and discharging operation as shown in Figure 7 (b)

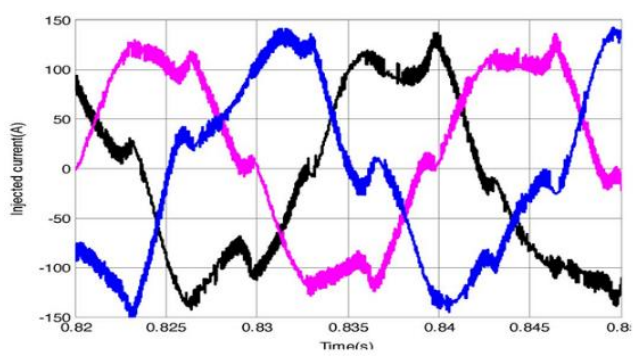

Figure 5. Three phase injected inverter Current.

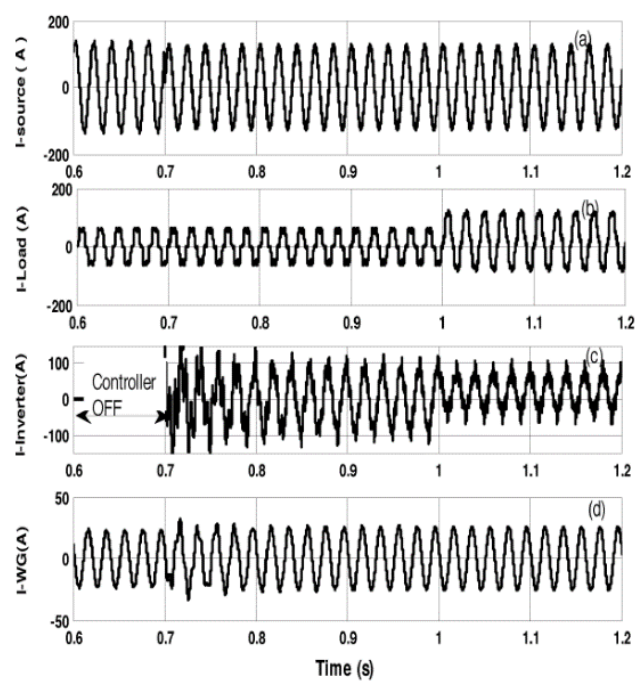

Figure 6. (a) Source Current. (b) Load Current. (c) Inverter Injected Current (d) Wind generator (Induction generator) current.
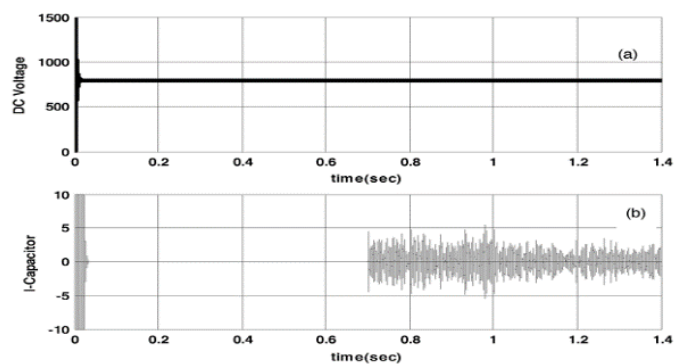

Figure 7. (a) DC link voltage. (b) Current through Capacitor.

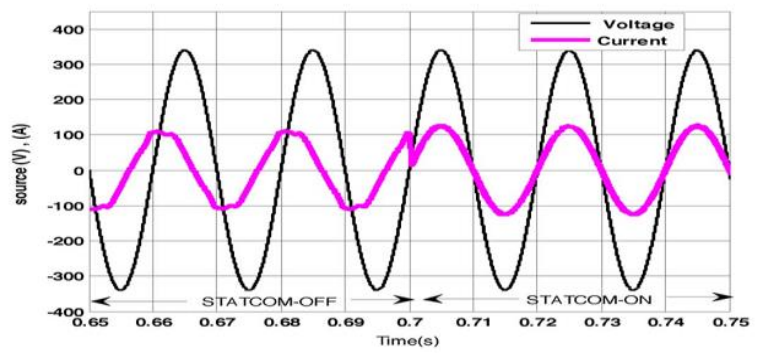

Figure 8. Supply Voltage and Current at PCC.

C. Power Quality Improvement

Power quality is affected by the nonlinear loads as such loads inject harmonics in the grid. Wind generators also have negative impact on power quality. Thus the purity of voltage and current 
waveforms on grid side and wind generator side cannot be assured. The STATCOM output voltage and injected current are adjusted as per the power quality parameters sensed by the hysteresis controller from the grid. The high-speed operation of controller ensures reliable power quality norms at the PCC. The STATCOM output voltage is shown in the figure. The source side voltage and the current plot are shown in the figure; the plot clearly shows that power factor becomes near unity when the STATCOM is switched on. The harmonics in the source side current before and after the beginning of STATCOM operation is carried out. When STATCOM is made on significant reduction of harmonics from an initial value of $4.71 \%$ is observed. The source current waveform when STATCOM is on is shown in the figure.

The model not only improves the power quality but also supports the loads with its batteries. It balances the supply and demand. This scheme also has the capabilities to support the loads in case of loss of generation, in such case power from batteries can be supplied to the loads but for a limited time.
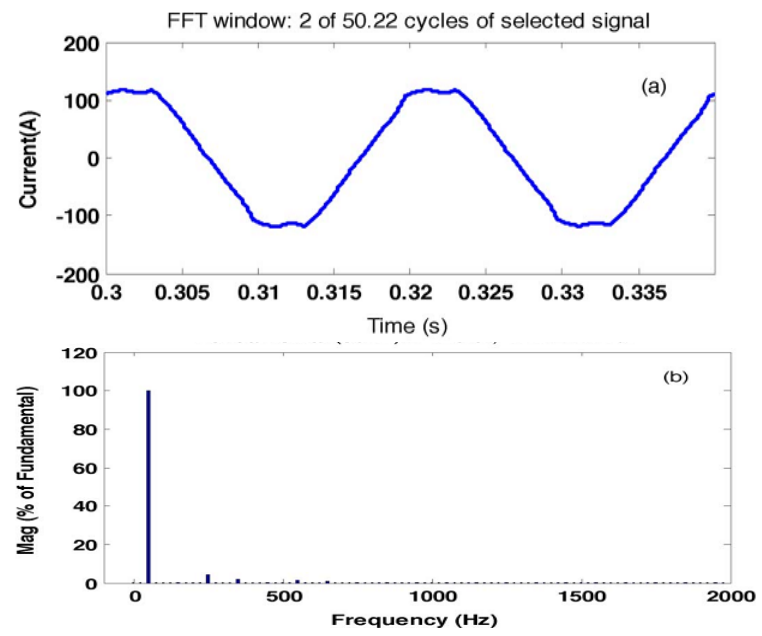

Figure. 9 (a) Source Current. (b) FFT of source current.

\section{Conclusions}

The paper presents STATCOM based battery energy storage system. STATCOM is a voltage source inverter having lgbt as its switches. The switching of igbt's is controlled by the hysteresis controller. Therefore the power flow from and to the BESS system is controlled effectively as per the switching command generated by the controller. The entire STACOM-BESS system is modeled in MATLAB/Simulink. When STATCOM is in operation significant improvement in power quality is observed. Issues like voltage sag \swell, harmonic distortion, power factor voltage profile are properly tackled. When STATCOM in operation it injects current into the power grid at PCC which nullify the harmonic part of the source current. Therefore current and voltage at source side become in phase. A near unity power factor, therefore, can be maintained at the evacuating substation (PCC). By maintaining power quality norms at nearby substations of the wind generating farm forced tripping of connecting lines between pooling substation and evacuating substation can be avoided which improves the plant load factor and in terns revenues.

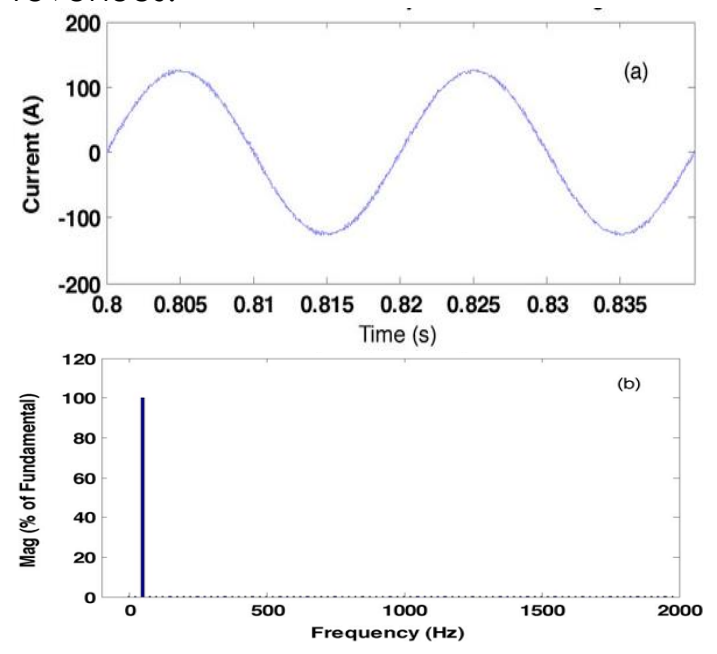

Figure 10. (a) Source Current. (b) FFT of source current.

\section{Acknowledgement}

This research did not receive any specific grant from funding agencies in the public, commercial, or not-for-profit sectors.

\section{References}

[1] Hook, K. S., Liu, Y., and Atcitty, S. (2006). Mitigation of the wind generation integration related power quality issues by energy storage. EPQU J., 12(2).

[2] Manel, J. (2006). Power electronic system for grid integration of renewable energy source: A survey. IEEE Trans. Ind. Electron., 53(4), 1002-1014.

[3] Han, C., Huang, A. Q., Baran, M., Bhattacharya, S., and Litzenberger, W. (2008). STATCOM impact study on the integration of a large wind farm into a weak loop power system. IEEE Trans. Energy Conv., 23(1), 226-232,

[4] Kinjo, T. and Senjyu, T. (2006). Output leveling of renewable energy by electric double layer capacitor applied for energy storage system. IEEETrans. Energy Conv., 21 (1).

[5] Bhatia, R. S., Jain, S. P., Jain, D. K., and Singh, B., Battery energy storage system for power 
conditioning of renewable energy sources. Proc. Int. Conf. Power Electron Drives System, $1,501-506$.

[6] Zeng, J., Yu, C. Qi, Q. and Yan, Z. (2004). A novel hysteresis current control for active power filter with a constant frequency. Elect. Power Syst. Res., vol. 68, pp. 75-82, 2004.

[7] J. Barros, De Apraiz, M., and Diego, R. I. (2007). Measurement of Subharmonics in Power Voltages. Power Tech, IEEE Lausanne, 1736 - 1740.

[8] Lei, Y., Mullane, A., Lightbody, G., and Yacamini, R. (2006). Modeling of the wind turbine with a doubly fed induction generator for grid integration studies. IEEE Trans. Energy Conversion, 21 (1), 257-264.

[9] Lu, C. F., Liu, C. C., and Wu, C. J. (1995). New dynamic models of lead-acid batteries. IEE Proc.-Gener. Trans. Distrib., 142 (4), 429-435.

[10] Salamah, Z. M., Casacca, M. A., and Lynch, W. A., (1992). A mathematical model for lead-acid batteries. IEEE Trans. Energy Conversion, 7(1), 93-97.

[11] Yang, Z., Shen, C., Zhang, L., Crow, M. L. and Atcitty, S. (2001). Integration of a STATCOM and battery energy storage. IEEE Trans. Power Syst., 16 (2), 254-260.

[12] Black, M., and Strbac, G. (2007). Value of bulk energy storage for managing wind power fluctuations. IEEE Trans. Energy Conversion, 22(1), 197-205.

[13] Spahic, E., Balzer, G. and Shakib, A. D. (2007). The impact of the 'wind farm battery' unit on the power system stability and control. Proc. IEEE Power Tech., Lausanne, 5, 485-490.

[14] Mohod S. W., and Aware, M. V. (2006). Grid power quality with variable speed wind energy conversion. Proc. IEEE Int. Conf. Power Electronic Drives and Energy System (PEDES), 1, 501-506.

[15] Mohod S. W., and Aware, M. V. (2008). Power quality issues \& it's mitigation technique in wind energy conversion. Proc. of IEEE Int. Conf. Quality Power \& Harmonic, 3.

[16] Milands, M. I., Cadavai, E. R., and Gonzalez, F. B. (2007). Comparison of control strategies for shunt active power filters in three phase four wire system. IEEE Trans. Power Electron. , 22 (1), 229-236.

[17] ZOU, C., WANG, B., and BAO, P. (2008). Application of STATCOM in Wind Farm. Electric Drive, 12, 1-10, 2008. 